\title{
Signs and Pedestrian Safety in Automated Transportation Systems
}

\author{
Haiyan Xie*, Luke Verplaetse \\ Department of Technology, Illinois State University, Normal IL, USA \\ Email address: \\ hxie@ilstu.edu (Haiyan Xie), lver@ilstu.edu (L. Verplaetse) \\ ${ }^{*}$ Corresponding author
}

To cite this article:

Haiyan Xie, Luke Verplaetse. Signs and Pedestrian Safety in Automated Transportation Systems. Automation, Control and Intelligent Systems. Vol. 7, No. 1, 2019, pp. 46-53. doi: 10.11648/j.acis.20190701.16

Received: April 18, 2019; Accepted: May 26, 2019; Published: June 15, 2019

\begin{abstract}
Motor-vehicle accidents have caused many safety concerns ever since cars have been on the road. With the implementation of cooperative and automated vehicles (CAVs) merging into the current crosswalks, signals, and concrete rules, the vehicle-pedestrian interactions create noteworthy safety issues. Through observational findings, intersections with higher signage and pedestrian signals had less likely of a chance for pedestrians to run into an altercation when compared to intersections with just crosswalks and no pedestrian signals. This research presents an optimization framework and an analytical solution with field observations to study whether the implementation of more pedestrian signals could have a great effect on vehicle/pedestrian incidents. The research implements the integrated methods of case studies, modeling and simulation using mathematical and statistical software on correlations and probabilities. This study adds minimal interference to the observations as they naturally occur. The study setting is non-contrived and maintained as natural environment. The collected data is continuous time series and measured using Chi-Square for analysis. After the identification of possible interactions between CAVs and pedestrians based on the data surveyed around the Illinois State University (ISU), this study finds that the safety of pedestrian relies on the intersection design of signs and signals more than the intelligence of CAVs (significance level $=95 \%$ ). This paper also discusses law enforcement and autonomous driving as a means of lowering pedestrian incidents at intersections. The developed mathematical analysis model and simulations help to verify the influences of transportation signs and intersection designs. The investigation innovatively demonstrates the feasibilities of different methods to protect the pedestrian safety while they enter intersections. The findings from this research can provide decision support for future transportation design and implementation rules of CAVs.
\end{abstract}

Keywords: Cooperative and Automated Vehicles (CAVs), Pedestrian, Safety, Signal Design, Crosswalk Analysis

\section{Introduction}

Pedestrians face dangerous situations while crossing intersections [1, 2]. The risks are caused both by the pedestrians themselves and the perceptions of machine-learning techniques [1]. It is highly possible for pedestrians to pose the challenges for cooperative and automated vehicles (CAVs) or self-driving cars, because other cars mostly behave in predictable ways or follow traffic rules carefully, but pedestrians can be rather erratic [2]. They can move in irregular directions, at any time, and without warning [1, 2]. Researchers made the assumptions that pedestrians understood the behaviors of other people when they approaching intersections [1-3]. For human drivers, they are able to distinguish the pedestrians who attempt to enter the intersections or roads in front of the vehicles from some ones who plan to wait for the bus or read on cell phones. However, for the CAVs using machine learning algorithms, it is difficult for them to pass a sidewalk full of pedestrians and distinguish at a glance if any of them are preparing to step in the road $[1,2]$. Increased safety measures would help to mitigate the dangerous situations [3, 4]. The purpose of this study is to make suggestions on how to decrease pedestrian incidents. Particularly, this research designs and implements an optimization framework and an analytical solution with field observations for intersection design of mixed transportation with human and vehicles.

This research implemented the mixed methods of case 
studies, modeling and simulation using mathematical and statistical software on correlations and probabilities. After literature review and methodology design, the data was collected from three intersections which had different levels of signage and signals around a college town in Illinois, U.S. This study added minimal interference to the observations as they naturally happened. The study setting was non-contrived and maintained as natural environment. The collected data is continuous time series and measured using Chi-Square for analysis. The assumption is that the intersections with less signage would have less driver compliance than those with traffic lights and pedestrian signals [4-6].

The variables in the study include the vehicles as the dependent variable and the situations of signage and pedestrian decisions as the independent variables [6, 7]. In addition, this research assumes that all vehicles are driving at approximately the speed limits of the particular city [5-7]. With some intersections being very busy, the authors accurately conducted the research only on the busiest side of the intersection. Hence the recorded traffic data would reflect the accurate situation. The traffic volumes are gathered from the Illinois Department of Transportation [3]. Another assumption is that the drivers are at fault once the pedestrian is in the intersection. The entire time frame of the study is 16 weeks long. The focus is the traffic situations of Normal, Illinois, which has 20,635 students [4]. This research assumes that half of the students walk to school, which is the foundation of the pedestrian volumes calculation. As explained in Section 4 "Data Analysis", the authors built mathematical models and performed simulations to study the relationships between accelerations, speeds and risks under different intersection designs. The findings from this research provide decision support for the engineers and designers of transportation systems when they search for solutions to meet the challenges of the implementation of CAVs $[1,2]$.

\section{Literature Review}

Recent studies about pedestrian safety around the country focus on how to prevent casualties [5-7]. Researchers analyzed the different safety elements including rapid flashing beacons, flashing yellow beacons, and high visibility crosswalk marking [5]. The implementations of these elements had significant increases in pedestrian safety. The analysis of the before-after crash patterns showed a reduction in the pedestrian crash severity after the installation of the crosswalk enhancements [5]. Approximately 93\% of participants in a study noticed the difference between pedestrian countdown signals and standard pedestrian signals [6]. The participants stated that they prefer the pedestrian countdown signal and feel safer when they could ascertain the time left for crossing the roads. This shows that the increased implementations of signs and visible signals for pedestrians and drivers can lower crash severity and help pedestrians feel safer $[5,6]$. This research implements simulations for the pedestrian safety analysis at intersections with intention to show if signs and signals can lower pedestrian severity risk. This study also helps to make recommendations for future safety upgrades at intersections.

There are different solutions for pedestrian safety. A safety upgrade implemented in New York City allowed pedestrians a head start before the lights turn green [7]. The New York City transportation officials said that the head-starts were in the range from 7 to 11 seconds, with more time allowed for wider streets. The Transportation Department analyzed the head-start situations in 104 intersections and published a report in 2016 [7]. It found that after giving pedestrians head-starts, there was a significant decline in fatalities and severe injuries to pedestrians. This would also be cost effective because it would only require little programming. Other operative upgrades included single-lane roundabouts, sidewalks, exclusive pedestrian signal phasing, pedestrian refuge islands, and increased intensity of roadway lighting [8]. Retting et al. also suggested that promising upgrades included advance stop lines, in-pavement flashing lights, and automatic pedestrian detection at walk signals [8]. Researchers also suggested eliminating intersections at all costs [9]. They stated that local authorities should improve walkability by providing more sidewalks and separating travel lanes for motorized traffic and pedestrians in the areas with different land uses. Compact development might be able to support the creation of a safe walking environment [9].

For pedestrian safety, more lighting might be promising to reduce pedestrian crashes [8]. The simulations of visual impairments and glare situations showed that improved lighting designs could significantly reduce the frequencies of emergency braking $[8,9]$. Drivers could recognize pedestrians early and the distances at which the drivers first recognized them increased noticeably [9]. The enhanced lighting designs around intersections could help drivers to see the pedestrians that might otherwise be hard to recognize. This is also significant because although the highest frequencies of pedestrian crashes were during day time, the fatal and severe injuries were more associated with darkness [10]. During this study, the authors evaluated the sites during day time because of observation and survey limitations; but lighting around intersections is still a crucial factor in evaluating pedestrian safety.

The future is slowly adapting with the introduction of autonomous electric vehicles $[1,2]$. There is an increasing amount of electric vehicles taking the road, some of which are driving autonomously $[1,2,11,12]$. Driverless vehicles or CAVs can see in spots that a driver may not see. These CAVs can make quick and calculated decisions whereas a human might not be as fast. For example, Gilmore stated that with the automated light vehicles on guided routes, it would be safe, low-polluting, space-saving, and fuel-efficient [11]. According to the National Highway Traffic Safety Administration, the automated vehicles' potential to save lives and reduce injuries is rooted in one critical and tragic fact: 94 percent of serious crashes are due to human error [12]. Automated vehicles have the potential to remove human error from the crash equation, which helps to protect drivers and passengers, as well as bicyclists and pedestrians [12]. Although this is still years away, it is possible that pedestrians would be much safer due to 
autonomous vehicles.

Automated and cooperative vehicles (CAVs) also have ethics to deal with [13]. For example, people need to answer this question. With the choice of making multiple decisions that a human would not have time to react to, how does the car decide what action to take? Take an example when a pedestrian walks out and in front of a vehicle, the driver might have no time to react. Self-driving cars have the potential to make a better decision than a fast-impulsive human-decision that the driver must make in a split second. With that being said, what if there was a situation where a crash was not avoidable? Should the car always be programmed to minimize the number of deaths or always be programmed to save the passengers at all costs? People need to identify the ethical values, considerations, and principles that are best suited to on this pressing ethical issue $[12,13]$. Nyholm and Smids suggested thinking about how to specify and adopt those values, considerations and principles to the problem of how self-giving cars ought to be programmed to react to accident scenarios [13]. In other words, there is still a lot of work to do. This shows that even though self-driving cars can be safer, they will still never be $100 \%$ safe because of unpredictable situations. Although self-driving cars are still up and coming. Within the near future, self-driving cars would become prevalent, which urges people to deal with the ethics of dangerous situations needs in depth $[12,13]$.

Enforcement and education of pedestrian laws should be serious enforced. Possible strategies for prevention included the improved enforcement of pedestrian right-of-way laws, changed vehicle design with modification of the environment (particularly in urban areas), and improved training programs for children [14]. Introducing new means of communicating pedestrian safety and enforcement could decrease pedestrian incidents. There was a positive association between road safety education and participants' road crossing behaviors [15]. This means that people with higher knowledge of road laws have safer road crossing behaviors and is another reason why pedestrian education could greatly reduce pedestrian crashes $[14,15]$. For example, a study was conducted at the Johns Hopkins University Arts and Sciences campus that evaluated student pedestrians [16]. The results showed that as well as upgrading engineering methods, education and enforcement were also big parts of traffic safety. The effective ways to help education at a university level would be to have mandatory pedestrian safety session at new student orientation as well as develop a communications campaign on pedestrian risks to improve awareness and knowledge about how to travel safely as a pedestrian. Moreover, for enforcement around campus the university should increase traffic law enforcement especially around the beginning of the year in addition to the installations of speed cameras to reduce traffic speed [16]. More traffic cameras could also be beneficial in decreasing vehicle speeds as well as better enforcement especially during the beginning of the year.

With the understanding of multiple methods to increase pedestrian safety, there is still knowledge gap of quantitative evaluations of whether the implementation of more pedestrian signals could have a great effect on vehicle/pedestrian incidents. Furthermore, there should be an optimization framework and analytical solutions with field observations to study the systematic approach for the evaluations. The previous studies provide theoretical foundation for the identification of interactions between pedestrians and vehicles, especially the unpredictability of the possible behaviors of pedestrians. These pedestrian behaviors become the possible improvements for the designs of automated transportation systems.

\section{Methodology}

This research uses an observational design. The units of study are the interaction of vehicles and pedestrians as well as signage levels while crossing marked intersections. Figure 1 shows a brief model of the research methodology.

\begin{tabular}{|c|c|c|}
\hline \multicolumn{3}{|c|}{$\begin{array}{l}\text { Research Problem: Due to the limited police enforcement, } \\
\text { warning signs, and increased traffic, pedestrians face threatening } \\
\text { situations when trying to aoss streets around streets. }\end{array}$} \\
\hline $\begin{array}{l}\text { Research Strategies: } \\
\text { Mixed Methods of Case } \\
\text { Studies, Modeling and } \\
\text { Simulation, together with } \\
\text { Laboratory Experiment. }\end{array}$ & \multicolumn{2}{|c|}{$\begin{array}{l}\text { Data Collection: } \\
\text { Observations: The researchers } \\
\text { observe ped estrians as they } \\
\text { cross the streets. } \\
\text { Simulations: mathematical and } \\
\text { statistical software simulation } \\
\text { on correl ations and } \\
\text { probabilities. }\end{array}$} \\
\hline $\begin{array}{l}\text { Minimal. } \\
\text { Researchers will study } \\
\text { events as they naturally } \\
\text { occur. }\end{array}$ & \multicolumn{2}{|c|}{$\begin{array}{l}\text { Sampling Design: } \\
\text { Continuous Time Series data }\end{array}$} \\
\hline $\begin{array}{l}\text { Study Setting: } \\
\text { Non-contrived. } \\
\text { Field study on natural } \\
\text { environment. }\end{array}$ & \multicolumn{2}{|c|}{$\begin{array}{l}\text { Measurement: } \\
\text { Operational definition and use } \\
\text { of Chi-Square to analyze data }\end{array}$} \\
\hline $\begin{array}{l}\text { Unit of Analysis: } \\
\text { Dyad. } 3 \text { groups of the } \\
\text { pedestrian, vehicle and } \\
\text { signal designs }\end{array}$ & \multicolumn{2}{|c|}{$\begin{array}{l}\text { Time Horizon: } \\
\text { One-shot data: data is collected } \\
\text { between certain day-times. } \\
\text { This is a small time frame. } \\
\end{array}$} \\
\hline \multicolumn{3}{|l|}{ Data Analvsis: } \\
\hline $\begin{array}{l}\text { Task 1: Identification } \\
\text { of Interaction. } \\
\text { Pedestrian Behavior } \\
\text { Analysis; Applicable } \\
\text { laws; Possible } \\
\text { Improvem ents. }\end{array}$ & $\begin{array}{l}\frac{\text { Task 2: }}{\text { Evaluation. }} \\
\text { Detailed } \\
\text { simulation } \\
\text { and analysis; } \\
\text { List of tests. }\end{array}$ & $\begin{array}{l}\text { Task 3: Design } \\
\text { Guidelines. } \\
\text { Methods to } \\
\text { lower } \\
\text { pedestrian } \\
\text { incidents. }\end{array}$ \\
\hline
\end{tabular}

Figure 1. Research Methodology.

The study was conducted at three different intersections around the campus of Illinois State University in 2018. All intersections have different levels of signage and enforcement. In this study, an infraction is a mean to describe how many times a possibly harmful situation occurred at the defined intersection. A harmful situation is a violation of pedestrian laws in Illinois. A list of pedestrian laws is listed as follows (from cyberdriveillinois.com). 
A driver must come to a complete stop (and yield):

When a pedestrian is in a marked crosswalk.

On school days, when children are in close proximity to a school zone crosswalk.

When a pedestrian is in an unmarked crosswalk on the driver's side of the roadway and there are no traffic control signals.

When making a turn at any intersection.

When making a lawful turn on a red light after coming to a complete stop.

After coming to a complete stop at a stop sign or flashing red signal at an intersection.

When a pedestrian enters a crosswalk before the traffic light changed.

When a pedestrian is walking with a green light, to a walking person symbol or a walk signal.

When a pedestrian is leaving or entering a street or highway from an alley, building, private road or driveway.

When a pedestrian is entering an intersection with a flashing yellow arrow. (Bicycle and Pedestrian Safety, n.d.)

During data collection, the authors counted an "instance" as when a pedestrian was in the intersection and the vehicle on the opposite side of the street (a.k.a. the "far-side"). If there was more than one pedestrian traveling the same way at the same time in the intersection, this was only counted as one instance. The authors marked a " 1 " in a notebook if a vehicle attempted or did cross the street while the pedestrian was already in the crosswalk. The " 1 " is an "infraction". A " 0 " showed that the vehicle stopped and yielded to the pedestrian (no infraction). The data were then put into Excel and Minitab to evaluate the data further. Each sample was gathered on the same day of the week at the same time. After all the data from all three intersections were gathered, a Chi-Square test was used to evaluate the differences. The population and samples were random pedestrians and vehicles that crossed the intersection at the designated time of each observation. The randomness makes the data valid as well as the data being categorical. All the data in this study are categorized into mutually exclusive categories with no overlap.

The sites that were picked were based on annual average daily traffic data from the Illinois Department of Transportation [3] as well as intersections identified as heavy in vehicle and pedestrian traffic. Sites were also chosen with different levels of signage to help differentiate between the intersections. While doing early research it seemed that intersections with traffic lights and pedestrian light tended to have much higher compliance than those with just stop signs. Although environmental conditions, traffic, and pedestrian flow can change over time, these factors were also identified during each sample observation. The situation that a car crosses or attempts to cross an intersection while a pedestrian is present in the crosswalk, does not mean that it would always result in an accident. Not all pedestrian accidents are the fault of the driver. This study focuses on the vehicle and how they impact the pedestrian. This is due to the Illinois Department of Transportation City summary crash report from Normal, Illinois. It finds that of the 19-total number of persons involved in pedestrian crashes in 2016, 14 of them were crossing with a signal [17].

Figure 2 shows a challenging situation for the coordination between CAVs and pedestrians. In this research, the increasing number of CAVs $N(t) \in N$, where $t \in R$ is the time of CAVs entering the intersection. When a vehicle reaches the intersection at some instant $t$, the proposed optimization framework assigns a unique identity $\mathrm{i}=\mathrm{N}(\mathrm{t})+1$ that is an integer showing a first-in-first-out (FIFO) queue for the vehicle. The number $\mathrm{N}(\mathrm{t})$ can be reset only if no vehicles are inside the intersection. Assume $\mathrm{N}(\mathrm{t})=\{1, \ldots, \mathrm{N}(\mathrm{t})\}$, for the queue at the intersection. Each vehicle $i, i \in N(t)$, is a point mass moving along a specified lane with a state equation

$$
\begin{aligned}
& \dot{x}_{i}=f\left(t, x_{i}, u_{i}\right) \\
& x_{i}\left(t_{i}^{0}\right)=x_{i}^{0}
\end{aligned}
$$

Where $\mathrm{t} \in \mathrm{R}+$ is the time, $\mathrm{x}_{\mathrm{i}}(\mathrm{t}), \mathrm{u}_{\mathrm{i}}(\mathrm{t})$ are the state of the vehicle and control input, $t_{i}^{0}$ is the time that vehicle $i$ enters the intersection, and $\mathrm{x}_{\mathrm{i}}{ }_{\mathrm{i}}$ is the value of the initial state.

\section{Data Analysis}

This study was conducted for the purpose of determining which intersections have higher driver-pedestrian compliance when walking across the street with different signal design and to examine pedestrian driver interactions. The observational research method was used. Data were collected through the observations. In November of 2016, a total of 15 number of "infractions" were sited across all 3 intersections examined as seen in Table 1 . To put this into perspective Normal had 16 pedestrian crashes in 2016 that involved 19 people total. One of these crashes was a fatality. The ages of these people also sparked an interesting light on the topic. 9 of the 19 people involved in the 16 crashes were of pedestrians ages 18-24 [17]. Again, every instance that was observed does not $100 \%$ correlate to a pedestrian crash but these instances that were observed were all unlawful and potentially harmful to pedestrians.

The two sites without traffic lights or pedestrian signals had the highest share of incidents. All the observations were made on Thursdays from 1:00 PM -1:30 PM. The day of the week and time were all the same at each location to mitigate variation in pedestrian flow, vehicular traffic, lighting, and signal timing. The authors recorded the data of each intersection which including the system at which the traffic flow were regulated, whether that be by a stop sign or traffic signal. Other factors examined at each was if the intersection had signs stating that there was a crosswalk, painted marking on the ground, and other environmental factors. If a marked crosswalk was present, then the condition of the sign and paint were recorded. The posted speed limit was recorded but no means of measuring speed was used in this study. The pedestrian flow was examined for 30 minutes at each location and recorded with a notebook. Age and sex were excluded from the research. Pedestrian flow although was not accounted 
for, seemed to be relatively similar for all intersections.

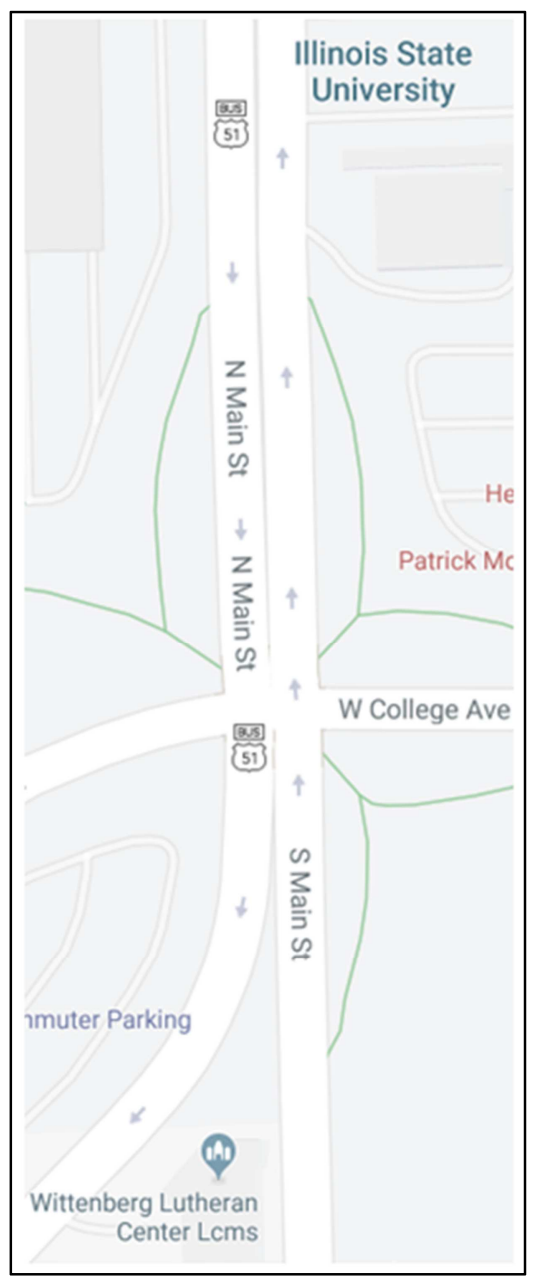

Figure 2. Coordination between Cavs and Pedestrians.

\subsection{Intersection $A$}

This intersection was located at South University St and West College Ave as shown in Figure 2. This intersection had the lowest amount of infractions due to several factors. The number of infractions is seen in Table 1. The date of observation was on $11 / 1 / 2018$. The weather conditions were slightly cloudy with a slight wind. The temperature was 45 degrees. Road conditions were average with slight potholes in the crosswalk. Tactile Paving for the visually impaired was also identified but only on the southeast corner of the intersection. This intersection had street lights that allowed the vehicles to see each corner of the intersection at night. As stated earlier, because of the high traffic volumes and the inability to gather information from all 4 sides of the street, the authors focused on only one side. In this case, the authors focused on the south side of the intersection. This side has 3 lanes. The northbound lanes have a left-hand turn lane and another that goes straight. The southbound lane is only one lane. The crosswalk was hatched with thick white lines on all 4 sides. The signage and signal design had traffic lights and pedestrian lights. No signage was present to notify the presence of a crosswalk. The posted speed limit was $30 \mathrm{mph}$ but $20 \mathrm{mph}$ on school days while children are present. This intersection while observed had $98 \%$ driver compliance. Because of the pedestrian lights and traffic lights, vehicles and pedestrians were more inclined to follow the rules. Out of the 42 possible instances, there was one Infraction at this intersection during the observations. This one infraction observed was due to a driver doing a right on red while a pedestrian was crossing the intersection.

\subsection{Intersection $B$}

This intersection was located at South University St. and West Beaufort St. This intersection had the highest amount of infractions due to several factors. The number of infractions is seen in Table 1. The date of observations was on 11/8/2018. The weather conditions were slightly cloudy with a light wind. The temperature was 36 degrees. Road conditions were average with slight potholes in the crosswalk and road. Tactile Paving for the visually impaired was also identified but only on the southwest, northeast, and southeast corners of the intersection. There were street lights, but it was hard at night to adequately see each corner of the intersection. Because of the high traffic volumes and the inability to gather information from all 4 sides of the street, the authors focused on only one side. In this case, the authors focused on the west of the intersection. This side has 4 lanes. The eastbound lanes have 2 lanes and the westbound also has 2 lanes. The crosswalk was 2 thick faded white line with no hatches. There was only presence of the crosswalk on the west and north side of the intersection. The signage and signal design had just stop signs and no mention of a crosswalk even though there was one there. The posted speed limit was $30 \mathrm{mph}$. This intersection while observed had 19\% infraction rate. Out of the observed 53 incidents, a total of 10 infractions were accounted. This is the highest out of all the sites tested. This high infraction rate could have to do with this intersection being 4 lanes which gives the driver "extra space" even though the pedestrian is still in the crosswalk and they must still stop and yield to them. The likelihood of a pedestrian-vehicle collision increases with the number of lanes and road width [18]. This means that even though it seems safer to cross it is more often not.

\subsection{Intersection $C$}

This intersection was located at South Fell Ave and West North Street. This intersection had the highest amount of infractions due to several factors. The number of infractions is seen in Table 1. The date of observations was on 11/15/2018. The weather conditions were wet and cloudy with a temperature of 28 degrees. Road conditions were great with no potholes. Tactile paving for the visually impaired was also identified on all corners of the intersection. This intersection had street lights that allowed the diver to see each corner of the intersection at night. Because of the high traffic volumes and the inability to gather information from all 4 sides of the street, the authors focused on only one side. In this case, the authors focused on the north side of the intersection. This side has 3 
lanes. One northbound lane, and 2 southbound lanes one being a left-hand turn lane. The crosswalk was 2 thick faded white line with hatches. There was only presence of the crosswalk on the west and north side of the intersection. The signage and signal design were a 4 way stop with stop signs and no mention of a crosswalk even though there was one there. The posted speed limit was $30 \mathrm{mph}$.

This intersection while observed had $8 \%$ infraction rate. Out of the observed 52 incidents, a total of 4 infractions were accounted. This is lower than Intersection 2 but still much higher than intersection 1 . Table 1 shows all the infractions vs intersection. Intersection $\mathrm{A}$ had the lowest number of infractions with 1 observed. Intersection B had the highest number of infractions with 10 observed. Intersection $\mathrm{C}$ was the 2 nd highest with 4 infractions observed. Using Minitab and Chi-Square, this research tests the association to determine whether two categorical variables are associated, specifically, whether pedestrian safety at different intersections depends on the intersection design. Table 1 shows the cross-tabulation in Chi-Square. Figure 3 shows the results from Matlab.

Table 1. Chi-Square Tests.

\begin{tabular}{llll}
\hline Intersection & Infractions & No Infractions & Total \\
\hline A & 1 & 41 & 42 \\
B & 10 & 43 & 53 \\
C & 4 & 48 & 52 \\
All & 15 & 132 & 147 \\
\hline
\end{tabular}

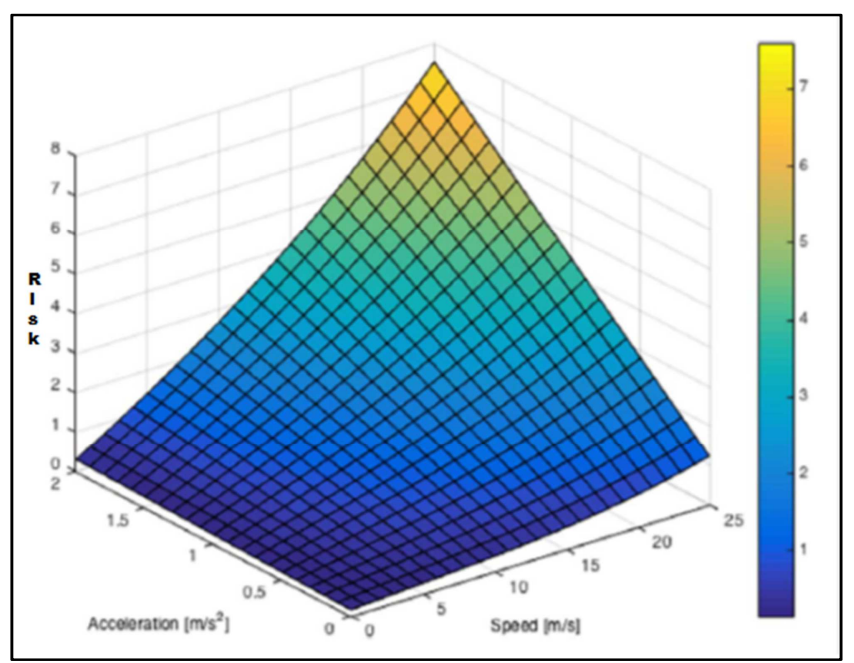

Figure 3. Risk level, vehicle acceleration and speed.

Figure 4 shows the results from Minitab. For this data, the Pearson Chi-Square statistic is 7.505 ( $\mathrm{p}$-value $=0.023$ ) and the likelihood ratio Chi-Square statistic is $7.895(\mathrm{p}$-value $=0.019)$. Both p- values are less than the significance level of 0.05 . Thus, the variables are associated and the safety of the pedestrian varies depending on the intersection design. The association between the variables is statistically significant. A significance level of 0.05 indicates a $5 \%$ risk of concluding that an association between the variables exists when there is no actual association.

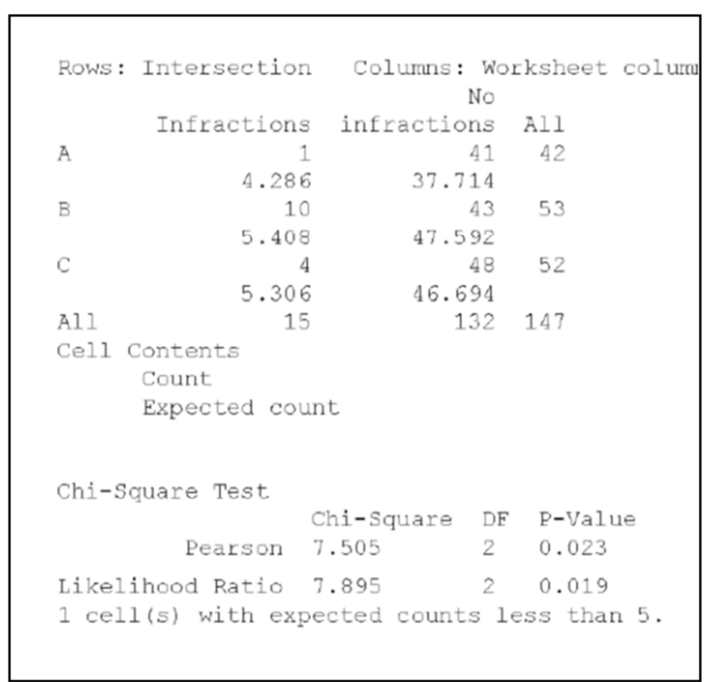

Figure 4. Chi-Square Test for Association.

\section{Discussion}

Even though traffic engineers have good intentions, the results suggest that crosswalk markings alone do not do enough to protect against pedestrians when crossing an intersection. Both intersections without pedestrian lights had a higher overall risk than that of the intersection with lights and other safety factors. Several study limitations should be kept in mind. First, this was an observational study, not a controlled experiment. The authors attempted to measure several relevant factors, but also other unmeasured site characteristics cannot be ruled out. Despite using vehicular flow data from the Illinois Department of Transportation, the pedestrian flow and vehicular traffic flow were important factors that could not be gathered. Pedestrian and vehicle count observed during the time interval on the same weekday and time of day may be the best indicator of long-term use levels but should be explored further. This is especially true during the summer when most students are not present.

A second limitation is that the study involved only three intersections. Although this study was focused on student safety around campus, the findings may not necessarily apply to other intersections. Nonetheless, student pedestrians are a known high-risk group in the area, and it is plausible that similar results relate to other intersections. Third, the study had limited ways to measure differences in the effects of specific crosswalk marking patterns. Forth this study was very limited in time and longer observational periods could be beneficial as well as videotaping.

Pedestrians may make unpredictable decisions to travel across roads. Nearly $40 \%$ of pedestrians incorrectly believed that traffic must stop for a pedestrian who is on the curb waiting to cross at a marked crosswalk [19]. Pedestrian education certainly needs to be increased and blame cannot be put solely on the driver. Older pedestrians tend to be more cautious than younger ones by waiting for longer gaps in traffic, but that this safety advantage was more than offset by their slower walking speeds [20]. This would all be mitigated with a use of more traffic signals and lights. Although this is 
not feasible at every single intersection, this also suggests that pedestrian education could be beneficial to helping pedestrian cross safely.

Although intersections were only observed that had traffic signals, pedestrians are still vulnerable at crossing locations where vehicles are accustom to proceed without interruptions. A pedestrian can enter the intersection with the legal right of way, but many drivers may be used to not stopping. Pedestrian safety depends deeply on the driver's alertness and how they follow the law. When a traffic signal or stop sign is present, pedestrians have a much stronger guarantee that traffic will stop and allow them safe passage [21]. This is true but pedestrian, as seen in the results, are still vulnerable at intersections that are marked especially ones that have limited signage.

Additional study could be done on the exact engineering practices of the signal design. More research could help explain uncertainty about the safety and effectiveness of different crosswalk markings, signage and signals as a preventative safety measure. This study finds that signal design is defiantly important at controlling vehicle and pedestrian and the enforcement must be consistent. Maintenance of the intersections could also help decrease pedestrian vulnerability as almost all the crosswalks observed had worn paint and lots of potholes. This goes for many of the intersections around ISU, not just the 3 observed in this research.

Self-driving cars promise to be safer and more effective at making decisions because of sensors and the ability to communicate other variables more effectively but this is still years away, and much work needs to go into the technology as well as the ethics in self-driving cars. The crosswalks without a traffic signal were associated with increased risks when compared to intersections with pedestrian signals and traffic lights. Increased pedestrian education could be beneficial. The implementation of different engineering methods, education and enforcement would all help ISU intersections be safer.

\section{Conclusion}

This research presents an optimized design of protocols for automated transportation systems with the focus on pedestrian-safety-related services. The proposed optimization framework is an analytical solution with field observations to study whether the implementation of more pedestrian signals could have a great effect on vehicle/pedestrian incidents. Based on literature data and field observations, the authors built models to simulate the pedestrian-vehicle interactions at different intersections. The mathematical and statistical analyses on the correlations and probabilities of accelerations, speeds and risks showed that this framework is effective in providing the insights for the designs of automated transportation systems. The limitations of this research include the observation duration and the simulation environments. To validate the generality of the framework, further research can be conducted on the investigation of how to help CAVs to choose the access modes to intersections.

\section{Acknowledgements}

This research is partially funded by the ISU Sustainability Grant (10400_01_510000000). The authors would like to thank Dr. Wei Shi for his support in methodology design.

\section{References}

[1] You, F., Zhang, R., Lie, G., Wang, H., Wen, H., \& Xu, J. (2015). Trajectory planning and tracking control for autonomous lane change maneuver based on the cooperative vehicle infrastructure system. Expert Systems with Applications, 42 (14), 5932-5946.

[2] Lee, J., \& Park, B. (2012). Development and evaluation of a cooperative vehicle intersection control algorithm under the connected vehicles environment. IEEE Transactions on Intelligent Transportation Systems, 13 (1), 81-90.

[3] Getting around Illinois. (n.d.). Retrieved from Illinois Department of Transportation:

https://www.gettingaroundillinois.com/gai.htm?mt=aadt.

[4] Jome, E. (2018, September 5). Freshman and graduate student numbers up at Illinois State. Retrieved from Illinois State University news:

https://news.illinoisstate.edu/2018/09/freshman-and-graduatestudent-numbers-up-at-illinois-state/

[5] Monsere, C. M., Kothuri, S., Rampa, A., \& Figliozzi, M. A. (2018). An Analysis of the Safety Effectiveness of pedestrian Crossing Enhancements in Oregon. Transportation Board 97th Anual Meeting, 17. Retrieved from https://trid.trb.org/view/1494553.

[6] Kwigizile, V., Oh, J.-S., Van Houten, R., Prieto, D., Boateng, R. Rodriguez, L., Andridge, P. (2015). Evaluation of Michigan's Engineering Improvement for Older Drivers. Western Michigan University, Kalamazoo; Michigan Department of Transportation, 148. Retrieved from https://trid.trb.org/view/1371139.

[7] Hu, W. (2017, November 24). Giving Pedestrians a Head Start Crossing Streets. Retrieved from New York Times: https://www.nytimes.com/2017/11/24/nyregion/pedestrians-ne w-york-walk-signals.html.

[8] Retting, R. A., Ferguson, S. A., \& McCartt, A. T. (2003). A Review of Evidence-Based Traffic Engineering Measures Designed to Reduce Pedestrian-Motor Vehicle Crashes. American Journal of Public Health, 1456-1463. Retrieved from https://ajph.aphapublications.org/doi/pdf/10.2105/AJPH.93.9. 1456.

[9] Chen, P., \& Zhou, J. (2016). Effects of the built environment on automobile-involved pedestrian crash frequency and risk. Journal of Transport \& Health, 448-456.

[10] Yanagisawa, M., Swanson, E., \& Najm, W. G. (2014). Target crashes and safety benefits estimation methodology for pedestrian crash avoidance/mitigation systems. United States. national Highway Traffic Safety Administration, 1-88. Retrieved from https://rosap.ntl.bts.gov/view/dot/12068J. Clerk Maxwell, A Treatise on Electricity and Magnetism, 3rd ed., vol. 2. Oxford: Clarendon, 1892, pp. 68-73.

[11] Gilmore, J. (2000). How Radical Measures Can End A century of Slaughter on the Roads. Traffic Engineering \& Control, 361-362. Retrieved from https://trid.trb.org/view/670841. 
[12] Automated Vehicle for safety. (n.d.). Retrieved from National Highway Traffic Safety Administration: https://www.nhtsa.gov /technology-innovation/automated-vehicles-safety\#issue-roadself-driving.

[13] Nyholm, S., \& Smids, J. (2016). The Ethics of Accident-Algorithms for Self-Driving Cars: Ethical Theory and Moral Practice, 1275-1289. Retrieved from https://link.springer.com/article/10.1007/s10677-016-9745-2.

[14] Rivara, F. P., Reay, D. T., \& Bergman, A. B. (1989). Analysis of Fatal Pedestrian Injuries in King County, WA and Prospects for Prevention. Public Health Reports, 293-297. Retrieved from https://trid.trb.org/view/354285.

[15] Ibrahim, J. M., Day, H., Hirshon, J. M., \& El-Setouhy, M. (2012). Road Risk-Perception and Pedestrian Injuries among Students at Ain Shams University, Cairo, Egypt. Journal of Injury and Violence Research, 4(2), 65-72. Retrieved from https://trid.trb.org/view/1163272.

[16] Pollack, K. M., Gielen, A. C., Mohad Ismail, M. N., Mitzner, M., Wu, M., \& Links, J. M. (2014). Investigating and improving pedestrian safety in an urban environment. Injury Epidemiology, 1-9. Retrieved from https://www.ncbi.nlm.nih. gov/pmc/articles/PMC5005641/.
[17] Illinois Department of Transportation. (2016, April 4). Retrieved from City Summary Crash Report: Normal Illinois: http://apps.dot.illinois.gov/eplan/desenv/crash/City\%20Summ aries/Year\%202016/Normal.pdf.

[18] Ukkusuri, S., Maranda-Mareno, L. F., Ramadurai, G., \& Isa-Tavarez, J. (2012). The role of built environment on pedestrian crash frequency. Safety Science, 1141-1151. Retrieved from https://www.sciencedirect.com/science/article/pii/S092575351 $1002578 \#$ !

[19] Tidwell, J. E., \& Doyle, D. P. (1995). Driver and Pedestrian Comprehension of Pedestrian Law and Traffic Control Devices. Transportation Research Record, 119-128.

[20] Oxley, J., Fildes, B., Ihsen, E., Charlton, J., \& Day, R. (1997). Differences in traffic judgements between young and old adult pedestrians. Accident Analysis \& Prevention, 29 (6), 839-847. Retrieved from https://doi.org/10.1016/S0001-4575 (97) 00053-5.

[21] Koepsell, T., McCloskey, L., \& Wolf, M. (2002). Crosswalk Markings and the Risk of Pedestrian-Motor Vehicle Collisions in Older Pedestrians. JAMA, 2136-2143. 